\title{
Diagnosis and Treatment of Infected Shoulder Arthroplasty: Current Concepts Review
}

\author{
Giulio Maria Marcheggiani Muccioli ${ }^{1}$ Enrico Guerra ${ }^{2}$ Tommaso Roberti di Sarsina ${ }^{1}$ Domenico Alesi ${ }^{1}$ \\ Stefano Fratini ${ }^{1}$ Eugenio Cammisa ${ }^{1}$ Vito Gaetano Rinaldi ${ }^{1}$ Giada Lullini ${ }^{3}$ Roberto Rotini ${ }^{2}$ \\ Stefano Zaffagnini ${ }^{1}$ \\ ${ }^{1}$ II Orthopaedic and Traumatologic Clinic, Istituto Ortopedico Rizzoli, \\ Bologna, Italy \\ 2 Shoulder and Elbow Unit, Istituto Ortopedico Rizzoli, Bologna, Italy \\ ${ }^{3}$ Laboratory of Movement Analysis and Functional-Clinical Evaluation \\ of Prosthesis, Istituto Ortopedico Rizzoli, Bologna, Italy \\ Address for correspondence Giulio Maria Marcheggiani Muccioli, MD, \\ PhD, II Orthopaedic and Traumatologic Clinic, Istituto Ortopedico \\ Rizzoli, Via di Barbiano 1/10, 40136, Bologna, Italy \\ (e-mail: marcheggianimuccioli@me.com).
}
Abstract
Keywords
- infection
- shoulder
- prosthesis
- diagnosis
- treatment

Periprosthetic shoulder infection (PSI) is an emerging pathology which requires many improvements in diagnosis and treatment to obtain a satisfying success rate. Different approaches have been described. This article summarizes current concepts of diagnostic process and main treatments described in the literature.

\section{Introduction}

The number of shoulder arthroplasty performed every year shows how this procedure is becoming increasingly common in the field of prosthetic surgery. In 2015, 8,180 primary total shoulder arthroplasty and 8,181 hemiarthroplasty were performed in the Emilia Romagna Region of Italy. ${ }^{1}$

Orthopaedic surgeons are now facing the main complications of shoulder arthroplasty, above all infections. Several reviews and original articles have been published in the literature regarding the management of periprosthetic shoulder infection (PSI).

\section{Diagnosis}

PSI represents a major complication with a reported incidence rate between 1 and $4 \%$ in primary arthroplasty and even higher after revision surgery. However, there is still a lack of consensus about the diagnostic and therapeutic strategies. $^{2-5}$ Diagnosis is not always easy and mostly consists of a combination of clinical signs and history, laboratory tests, and radiological investigation, such as conventional radiography, microbiological swabs, and in selected cases, scintigraphy. ${ }^{6}$ Some comorbidities, such as diabetes mellitus, lupus erythematosus, and rheumatoid arthritis increase susceptibility to infection. In addition, immunosuppressive chemotherapy, systemic or locally-injected steroid therapy or previous operations of the affected shoulder are considered as predisposing factors to infections in shoulder arthroplasty. . $^{7,8}$

Most patients with infected shoulder prosthesis refer pain and/or limited range of motion. ${ }^{9}$ However, not always signs and symptoms of infection are clearly present. Therefore, there is a consensus in considering each painful shoulder joint as potentially infected to perform a detailed diagnostic investigation. ${ }^{9}$ Time of onset of clinical signs of infection is relevant since it will influence treatment choice ( - Table $\mathbf{1})$.

Patients should be evaluated with high-quality radiographs, in anteroposterior and axillary lateral projections to rule out different causes of shoulder pain and dysfunctions that can mimic or coexist with periprosthetic shoulder infection. ${ }^{10}$ Laboratory examination should include a complete blood count (CBC) with differential, erythrocyte sedimentation rate (ESR), and C-reactive protein (CRP).,11,12 X-rays will received

March 2, 2018

accepted after revision

October 7, 2018

published online

December 10, 2018
DOI https://doi.org/

10.1055/s-0038-1675800. ISSN 2282-4324.
Copyright $\odot 2018$ Georg Thieme Verlag License terms

KG Stuttgart · New York 
Table 1 Classification of periprosthetic shoulder infection ${ }^{18}$

\begin{tabular}{|l|l|}
\hline Type of infection & Time period of infection \\
\hline Type I & Positive cultures at time of revision \\
\hline Type II & $\begin{array}{l}\text { Acute infection within } 30 \text { days } \\
\text { of surgery }\end{array}$ \\
\hline Type III & $\begin{array}{l}\text { Acute hematogenous infection } \\
>30 \text { days }\end{array}$ \\
\hline Type IV & Chronic infection \\
\hline
\end{tabular}

be often normal in case of early infection while periprosthetic osteopenia, osteolysis, or pseudosubluxation of the humeral head component could appear in case of subacute or late infection. ${ }^{13}$ MRI or ultrasonography can be used to detect surrounding osteomyelitis or abscesses. Scintigraphy should be reserved to doubtful cases only. Peripheral leucocyte count is usually within normal range, as is the neutrophil cell distribution. ESR and CRP should be crtitically evaluated, since they are aspecific markers of inflammation and may be not elevated in case of a Propionibacterium Acnes infection. As a rule, in case of a high clinical suspect for deep infection, aspiration of glenohumeral joint should be performed. Synovial fluid analysis should include cell count with differential; gram stain, cultures for aerobes, anaerobes, fungi, and mycobacteria. Some bacterical specimen, such as $P$. acnes, can take up to 3 to 4 weeks for positive cultures. ${ }^{14}$ Gram stain is positive in $75 \%$ of proven cases of infection, cultures are positive in $80 \%$ of cases. A negative gram stain or culture from an aspiration; however, does not rule out infection. 3,11,15

\section{Microbiology}

Weber et $\mathrm{al}^{9}$ found out that intraoperative swabs of all patients of his case series showed positive cultures identical to preoperative swabs and sustained that joint aspirations are important but antibiotic treatment needs to be stopped at least 14 days prior to aspiration in order not to influence cultures results. The most common bacterical specimens identified within cultures were: Staphylococcus epidermidis, P. acnes, Staphylococcus aureus (methicillin-sensitive), Streptococcus agalactiae, and Enterococcus faecalis. ${ }^{9}$ Threshold values for diagnostic synovial leukocyte count are still an active area of debate. ${ }^{16}$ Bauer et al suggested that a periprosthetic synovial fluid white blood-cell count of $>500$ cells/ $\mathrm{mL}$ is suggestive of infection. ${ }^{17}$ Pottinger et al demonstrated that male sex, cloudy synovial fluid, humeral osteolysis and loosening, glenoid wear, and periprosthetic membrane formation are associated to an increase of $P$. acnes positive culture growth. $^{14}$

\section{Therapeutic Options}

Since infection is a main cause for shoulder arthroplasty failure, it is important to plan the operative treatment. First patient's medical history and current medical status should be investigated to assess the eligibility to undergo one or more surgical procedures. Treatment options include antibiotic suppression, irrigation, and debridement with prosthesis retention, resection arthroplasty, one-stage exchange, or two-stage reimplantation (use of antibiotic spacer and delayed reimplantation). ${ }^{10}$

Treatment choice depends on several factors, such as timing of diagnosis, virulence of the bacterial species, patients' overall health, soft tissue and bone integrity, patient's age, and expectations. The ideal outcome after surgical treatment would be infection eradication with minimal loss of function or residual pain. ${ }^{18}$

Hackett et $\mathrm{al}^{18} \mathrm{drafted}$ an algorithm about management of PSI depending on the type of infection ( - Table 2 ). If positive cultures are isolated at time of revision the indication is the treatment with organism specific antibiotic and close observation. If the infection appears within 30 days after surgery, a surgical debridement with polyethylene exchange is appropriate. In case of acute hematogenous infection 30 days or more after surgery, surgical debridement with implant removal, resection arthroplasty, revision with one-stage or two-stage procedure with antibiotic spacer, followed by species directed antibiotic administration are treatment choices. ${ }^{3,9,11,15,19-26}$ Finally, in case of chronic infection in low demanding patients or patients not eligible for implant revision, surgical debridement with implant removal, antibiotic spacer placement, or simple resection arthroplasty should be the definitive treatments. ${ }^{9,20,27}$

PSI are commonly treated with a two-stage procedure being the solution with the best compromise between a reliable eradication of the infection and a satisfying functional outcome after surgery. ${ }^{21}$ In patients with PSIs, especially those with low virulence infections, a two-stage revision represents a viable treatment option for eradicating infection and restoring function. However, it is important to consider the risk of recurrent infections and postoperative complications in this challenging patient population. ${ }^{28}$ One-

Table 2 Treatment options for periprosthetic infections ${ }^{18}$

\begin{tabular}{|l|l|}
\hline Type of infection & Treatment \\
\hline Type I & Organism specific antibiotic treatment with close observation \\
\hline Type II & Surgical debridement with retention of prosthesis \\
\hline Type III & Surgical debridement with retention of implants or two-stage treatment with antibiotic spacer \\
\hline Type IV & $\begin{array}{l}\text { Surgical debridement with implant removal, temporary antibiotic spacer placement and } \\
\text { delayed reimplantation }\end{array}$ \\
\hline
\end{tabular}




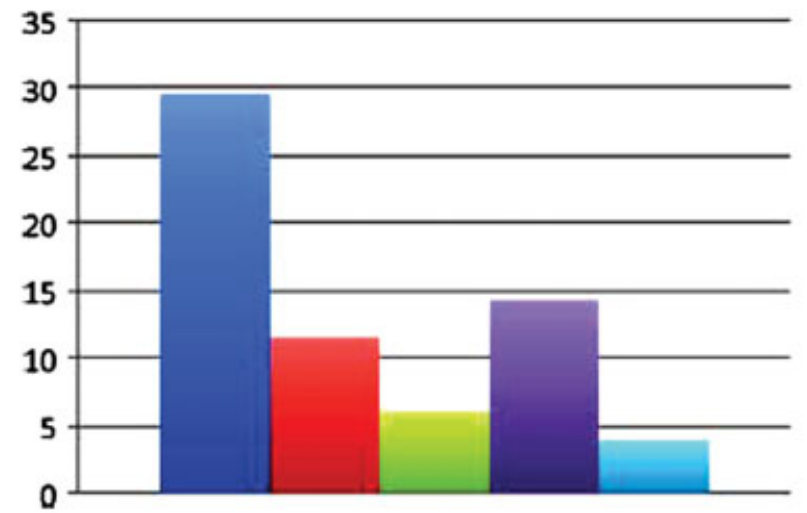

\author{
DEBRIDEMENT \\ a RESECTION \\ ARTHROPLASTY \\ = SPACER \\ - 2-STAGE REVISION \\ - 1-STAGE REVISION
}

Fig. 1 Persistent infection rate after different surgical treatment of infected shoulder prosthesis. ${ }^{29}$

stage revision shoulder arthroplasty is usually performed in super-specialized centers with dedicated surgical theaters and specialized departments for infected arthroplasty treatment. ${ }^{21}$ Most studies on one-stage revision surgery reported high reinfection rates while successful elimination of infection is achieved with a two-staged procedure. This event could be explained with the lack of organism identification prior to reimplantation. ${ }^{18}$ Marcheggiani Muccioli et al analyzed persistent infection rate after different surgical treatment of infected shoulder arthroplasty. ${ }^{29}$ These results showed how debridement has significantly higher rates (29.6\%) than almost any other procedure (-Fig. 1).

Revision reported better functional outcomes compared with nonrevision procedures. Moreover, timing of debridement is controversial. Although, early serial washouts ( $<2$ weeks postoperatively) were reported to eradicate infection and preserve motion, ${ }^{3}$ the high risk of persistent infection with debridement should be considered. ${ }^{30}$ Debridement in late infections (> 12 months) was shown to be ineffective. ${ }^{3}$ Based on these results, debridement with retention of the prosthesis is not recommended in the treatment of infected shoulder arthroplasty. Rispoli et $\mathrm{al}^{31}$ reported high rates of patient dissatisfaction (89\%) when treated with resection artrhroplasty, although they reported no persistent infections with a mean of 8.2-year follow-up. Therefore, it was concluded that pain relief could not be guaranteed with this procedure. Resection arthroplasty is often considered as an end stage procedure when all other options failed. ${ }^{9}$

Even though permanent spacers have a poor functional outcome and a low patient satisfaction, this procedure was found to have a high success rate in infections treatment. Permanent spacers are still a viable option as a salvage procedure for unresponsive PSIs and for low-demanding patients or patients not eligible for complex revision surgeries. ${ }^{29}$

\section{Conclusion}

PSI is an important complication after shoulder arthroplasty and is often associated to high morbidity. It poses a great burden to the patient and a significant technical challenge to the surgeon. Patients with a painful shoulder or limited range of motion should be carefully investigated to rule out a possible infection. With the increasing awareness of $P$. acnes, as the organism responsible for periprosthetic infections, shoulder surgeons have become more concerned with patients who present with a painful shoulder following arthroplasty. ${ }^{9}$ While some investigators reported good results with one-stage revisions, more reproducible results have been shown with the two-stage revision. As diagnostic criteria and identification of organisms prior to explant improves, one-stage revisions may show more promise in the future.

Conflict of Interest

None declared.

\section{References}

1 . Report of R.I.P.O: regional register of orthopaedic prosthetic implantology. Available at: https://ripo.cineca.it/pdf/relazione_2016_v19_inglese.pdf. Accessed February 22, 2018

2 Boileau P, Sinnerton RJ, Chuinard C, Walch G. Arthroplasty of the shoulder. J Bone Joint Surg Br 2006;88(05):562-575

3 Coste JS, Reig S, Trojani C, Berg M, Walch G, Boileau P. The management of infection in arthroplasty of the shoulder. J Bone Joint Surg Br 2004;86(01):65-69

4 Haines JF, Trail IA, Nuttall D, Birch A, Barrow A. The results of arthroplasty in osteoarthritis of the shoulder. J Bone Joint Surg Br 2006;88(04):496-501

5 Sperling JW, Kozak TK, Hanssen AD, Cofield RH. Infection after shoulder arthroplasty. Clin Orthop Relat Res 2001;(382):206-216

6 Topolski MS, Chin PYK, Sperling JW, Cofield RH. Revision shoulder arthroplasty with positive intraoperative cultures: the value of preoperative studies and intraoperative histology. J Shoulder Elbow Surg 2006;15(04):402-406

7 Wirth MA, Rockwood CA Jr. Complications of total shoulderreplacement arthroplasty. J Bone Joint Surg Am 1996;78(04): 603-616

8 Zeller V, Ghorbani A, Strady C, Leonard P, Mamoudy P, Desplaces $\mathrm{N}$. Propionibacterium acnes: an agent of prosthetic joint infection and colonization. J Infect 2007;55(02):119-124

9 Weber P, Utzschneider S, Sadoghi P, Andress H-J, Jansson V, Müller PE. Management of the infected shoulder prosthesis: a retrospective analysis and review of the literature. Int Orthop 2011;35 (03):365-373

10 Mook WR, Garrigues GE. Diagnosis and management of periprosthetic shoulder infections.J Bone Joint Surg Am 2014;96(11):956-965

11 Sperling JW, Cofield RH, Torchia ME, Hanssen AD. Infection after shoulder instability surgery. Clin Orthop Relat Res 2003;(414): 61-64 
12 Themistocleous G, Zalavras C, Stine I, Zachos V, Itamura J. Prolonged implantation of an antibiotic cement spacer for management of shoulder sepsis in compromised patients. J Shoulder Elbow Surg 2007;16(06):701-705

13 Brems JJ. Complications of shoulder arthroplasty: infections, instability, and loosening. Instr Course Lect 2002;51:29-39

14 Pottinger P, Butler-Wu S, Neradilek MB, et al. Prognostic factors for bacterial cultures positive for Propionibacterium acnes and other organisms in a large series of revision shoulder arthroplasties performed for stiffness, pain, or loosening. J Bone Joint Surg Am 2012;94(22):2075-2083

15 Jerosch J, Schneppenheim M. Management of infected shoulder replacement. Arch Orthop Trauma Surg 2003;123(05):209-214

16 Parvizi J, Zmistowski B, Berbari EF, et al. New definition for periprosthetic joint infection: from the Workgroup of the Musculoskeletal Infection Society. Clin Orthop Relat Res 2011;469 (11):2992-2994

17 Bauer TW, Parvizi J, Kobayashi N, Krebs V. Diagnosis of periprosthetic infection. J Bone Joint Surg Am 2006;88(04):869-882

18 Hackett DJ Jr, Crosby LA. Evaluation and treatment of the infected shoulder arthroplasty. Bull Hosp Jt Dis (2013) 2013;71 (Suppl 2):88-93

19 Strickland JP, Sperling JW, Cofield RH. The results of two-stage reimplantation for infected shoulder replacement. J Bone Joint Surg Br 2008;90(04):460-465

20 Coffey MJ, Ely EE, Crosby LA. Treatment of glenohumeral sepsis with a commercially produced antibiotic-impregnated cement spacer. J Shoulder Elbow Surg 2010;19(06):868-873

21 Klatte TO, Junghans K, Al-Khateeb H, et al. Single-stage revision for peri-prosthetic shoulder infection: outcomes and results. Bone Joint J 2013;95-B(03):391-395
22 Romanò CL, Borens O, Monti L, Meani E, Stuyck J. What treatment for periprosthetic shoulder infection? Results from a multicentre retrospective series. Int Orthop 2012;36(05): 1011-1017

23 Mileti J, Sperling JW, Cofield RH. Reimplantation of a shoulder arthroplasty after a previous infected arthroplasty. J Shoulder Elbow Surg 2004;13(05):528-531

24 Prosthesis of antibiotic-loaded acrylic cement (PROSTALAC) Use for the treatment of infection after shoulder arthroplasty. JBJS 2004;93(21):2001-2009

25 Seitz WH Jr., Damacen H. Staged exchange arthroplasty for shoulder sepsis. J Arthroplast 2002;17(4, Suppl 1):36-40

26 Sabesan VJ, Ho JC, Kovacevic D, Iannotti JP. Two-stage reimplantation for treating prosthetic shoulder infections. Clin Orthop Relat Res 2011;469(09):2538-2543

27 Jawa A, Shi L, O'Brien T, et al. Prosthesis of antibiotic-loaded acrylic cement (PROSTALAC) use for the treatment of infection after shoulder arthroplasty. J Bone Joint Surg Am 2011;93(21): 2001-2009

28 Buchalter DB, Mahure SA, Mollon B, Yu S, Kwon YW, Zuckerman JD. Two-stage revision for infected shoulder arthroplasty. J Shoulder Elbow Surg 2017;26(06):939-947

29 Marcheggiani Muccioli GM, Huri G, Grassi A, et al. Surgical treatment of infected shoulder arthroplasty. A systematic review. Int Orthop 2017;41(04):823-830

30 Ortmaier R, Resch H, Hitzl W, Mayer M, Stundner O, Tauber M. Treatment strategies for infection after reverse shoulder arthroplasty. Eur J Orthop Surg Traumatol 2014;24(05):723-731

31 Rispoli DM, Sperling JW, Athwal GS, Schleck CD, Cofield RH. Pain relief and functional results after resection arthroplasty of the shoulder. J Bone Joint Surg Br 2007;89(09):1184-1187 